\title{
A theory of organized crime, corruption and economic growth
}

\author{
Keith Blackburn ${ }^{1}$ - Kyriakos C. Neanidis ${ }^{1}$. \\ Maria Paola Rana ${ }^{1}$
}

Received: 6 March 2017 / Accepted: 15 March 2017 / Published online: 5 April 2017

C The Author(s) 2017. This article is an open access publication

\begin{abstract}
We develop a framework for studying the interactions between organized crime and corruption, together with the individual and combined effects of these phenomena on economic growth. Criminal organizations co-exist with law-abiding productive agents and potentially corrupt law enforcers. The crime syndicate obstructs the economic activities of agents through extortion, and may pay bribes to law enforcers in return for their compliance in this. We show how organized crime has a negative effect on growth, and how this effect may be either enhanced or mitigated in the presence of corruption. The outcome depends critically on a trade-off generated when corruption exists, that between a lower supply of crimes and the probability these crimes are more likely to be successful.
\end{abstract}

Keywords Corruption · Economic growth · Organized crime

JEL Classification D73 $\cdot$ K49 · O43

\section{Introduction}

There is a strong presumption that organized crime typically involves implicit collusion with, or direct participation of, the public sector. In 1994, the United Nation's Naples Declaration officially recognized that organized crime has a "corrupting influence on fundamental social, economic and political institutions", and that the common practice of organized criminal networks is to use "violence, intimidation and corruption to earn

\footnotetext{
$凶$ Kyriakos C. Neanidis

kyriakos.neanidis@manchester.ac.uk

1 Department of Economics, Centre for Growth and Business Cycle Research,

University of Manchester, Manchester, UK
} 
profit or control territories or markets". ${ }^{1}$ More recently, a survey of public perceptions conducted by the Eurobarometer (2006) revealed that more than half of European citizens believe that most of the corruption in their countries is caused by organized crime.

It is not difficult to understand why criminal syndicates would want to lure public officials-law enforcers, in particular-into corruption. Doing so offers the prospect of greater opportunities to engage in illicit activities with less risk of detection and prosecution. Such activities (including drugs trafficking, money laundering and extortion) are likely to be more successful with the compliance of law enforcement officers who are willing to accept bribes in return for various favours (e.g., turning a blind eye against offences, providing information about police inquiries and falsifying reports about arrests). More generally, organized crime can foster corruption at all levels of public office by targeting different areas-the police, the judiciary and the political administration. ${ }^{2}$ The general conclusion of most observers and practitioners is that organized crime flourishes most when the functioning of society's public institutions is undermined by corruption. Evidence of this can be found in several empirical studies covering various countries in different regions of the world and at different stages of socio-economic development: examples include Mazzitelli (2007) for West Africa, Sergi and Qerimi (2007) for South-East Europe, and Buscaglia and Van Dijk (2003) for a more global sample of territories.

Theoretical work on the issue has focused largely on the role of corruption in influencing and compromising strategies to combat organized crime. Becker and Stigler (1974) were the first to point out that the payment of bribes by criminals to law enforcers can weaken the threat of prosecution for criminal activity, suggesting that deterring such activity could be strengthened by remunerating public enforcers sufficiently well and/or paying private enforcers according to performance. These ideas were taken up in subsequent work which raised qualifications and questions about the proposals (e.g., Besley and MacLaren 1993; Mookherjee and Png 1992). In a similar vein, Bowles and Garoupa (1997) showed why the standard prescription of imposing the maximum fine on criminals may not be optimal when there is complicity between the criminal and arresting officer at the expense of the police department. Chang et al. (2000) introduce subjective psychic costs of corruption (moral shame and social stigma), demonstrating how social norms may create conditions under which an increase in fines for criminal activity are counter-productive. Along related lines, Kugler et al. (2003) identify circumstances where strategic complementarities between corruption and organized crime mean that tougher sanctions on crime produce higher rates of crime. From different perspectives, Garoupa and Klerman (2004) show that it is optimal to use non-monetary penalties against crime (e.g., imprisonment) more frequently in the presence, than in absence, of corruption, whilst Polinsky and Shavell

\footnotetext{
1 UN GA Resolution 49/159 Naples Political Declaration and Global Action against Organized Transnational Crime (23/121994); UN GA Resolution 1996/27 Implementation of the Naples Political Declaration and Global Action Plan against Organized Transnational Crime (24/07/1996).

2 This is evidenced in a report by the Center for the Study of Democracy (2010) which focuses on the links between organized crime and corruption in 27 European Member States using a statistical analysis of various indicators and interviews.
} 
(2001) suggest that sanctions against corruption, rather than sanctions against crime, are optimal in mitigating criminal behavior.

Whilst the foregoing research has delivered important results and yielded valuable insights, there is still considerable room for further investigation into the link between corruption and organized crime. A particularly fertile area for investigation is the extent to which this link may have an influence on overall economic performance. This is the theme of the present paper, which takes a step beyond the microeconomic (partial equilibrium) analysis of individual decision making (as exemplified above) towards the relatively unexplored macroeconomic (general equilibrium) analysis of aggregate outcomes (growth and development). The paper develops a series of analytical models in pursuing this new avenue of research.

We develop a framework for studying the interactions between organized crime and corruption, together with the individual and combined effects of these phenomena on economic growth. This framework describes an environment in which a criminal organization co-exists with law-abiding productive agents and potentially corrupt law enforcers. The crime syndicate obstructs the economic activities of agents through extortion, and may pay bribes to law enforcers in return for their compliance in this. We first show how the presence of organized crime on its own reduces economic performance by deterring agents from engaging in growth-promoting ventures (capital production). We then show how this effect may be either exacerbated or mitigated by the coexistence of both organized crime and corruption. Simply put, our analysis suggests that growth may be either higher or lower in a crime-only environment than in a crime-plus-corruption environment.

To be more specific, we develop an overlapping generations endogenous growth model where some agents are entrepreneurs that make investment decisions. Entrepreneurs are heterogeneous in their cost of entrepreneurial effort, and as a result, the measure of them who decide to invest depends on their perceived effective rate of return. It is this effort that directly maps into economic activity and determines the economic growth rate. Organized crime takes the form of a tax (extortion) on the expected returns of to-be entrepreneurs, and, thus, lowers the equilibrium growth rate compared to the economy without crime. Corruption takes the form of a tax (bribes to law enforcers) on the expected returns of criminals, which, in turn, hurts the entrepreneurs' expected investment returns and economic growth. The presence of corruption has two effects. It reduces the supply of crimes, but makes crimes that happen more likely to be successful. This gives rise to an ambiguity of the comparative static over the equilibrium growth rate with crime as compared to the growth rate with both crime and corruption. This finding highlights the importance of treating jointly the two illegal phenomena of organized crime and corruption in the context of growth analysis.

The remainder of the paper is divided into four parts. Section 2 presents an economy without any illicit activities. Section 3 introduces organized crime, whilst Sect. 4 further introduces corruption. Section 5 compares the macroeconomic outcomes of the two environments: an economy with organized crime only versus an economy riddled with both types of illegalities. Some concluding remarks are given in Sect. 6. 


\section{An economy without illegalities}

The general framework that we use for our theoretical analysis describes a dynamic, endogenously growing economy which is populated by heterogeneous agents engaged in different occupations. The engine of growth is capital accumulation, and the set of occupations may include both legal (productive) and illegal (non-productive) activities. The former consist of the production of output and capital, together with the enforcement of governance. The latter consist of illicit profiteering by private individuals and public officials. We begin by describing the benchmark scenario in which the economy is free from any malevolent behavior. Subsequently, we introduce such behavior and explore the implications thereof.

We consider an overlapping generations economy in which there is a constant population of two-period-lived agents. Each generation of agents is divided at birth into two groups of citizens - a unit mass of households (or workers) and a unit mass of firms (or entrepreneurs). The former are suppliers of labor when young and consumers of output when old. The latter are (potential) producers of capital when young, and producers and consumers of output when old. All agents are risk neutral and all markets are competitive. We proceed with our formal description of the environment with reference to the behavior of agents of generation $t$.

\subsection{Workers}

Each young worker supplies one unit of labor inelastically to old entrepreneurs (producers of output) in return for a wage of $w_{t}$. A worker can save this income in two ways. The first is by accessing some storage technology which pays a fixed rate of return of $\rho$. The second is by making loans to young entrepreneurs (producers of capital), the rate of interest on which is also $\rho$ by virtue of competition between lenders. The proceeds of savings are used to finance retirement consumption.

\subsection{Entrepreneurs}

The ultimate activity of entrepreneurs is the manufacture of final output in the second period of their lives. The inputs to manufacturing are labor (hired from young households of the next generation) and capital (acquired from investment projects undertaken previously by firms of the current generation). ${ }^{3}$ A mature entrepreneur employing $n_{t+1}$ units of labor and $k_{t+1}$ units of capital is able to produce $y_{t+1}$ units of output according to

$$
y_{t+1}=n_{t+1}^{\alpha} k_{t+1}^{1-\alpha} K_{t+1}^{\alpha}
$$

\footnotetext{
${ }^{3}$ We abstract from the use of human capital as an input, although one could visualise a scenario where organized crime and corruption can discourage the accumulation of knowledge. Blackburn and Chivers (2015) consider a model where agents are not prevented from investing in human capital but it is not in their interests to do so because the loss associated with a risky venture is too great to make the venture attractive, even if it offers the prospect of high rewards. A similar principle can apply when agents decide on their level of human capital investment when operating within a risky environment, riddled with illegal activities.
} 
( $\alpha \in(0,1))$ where $K_{t+1}$ denotes the aggregate stock of capital. ${ }^{4}$ Labor is hired at the competitively determined wage rate $w_{t+1}$, whilst capital is rented at the competitively determined interest rate $i_{t+1}$. If an entrepreneur produced $\kappa_{t+1}$ units of capital when young, then he is a net borrower of capital if $k_{t+1}-\kappa_{t+1}>0$ and a net lender of capital if $k_{t+1}-\kappa_{t+1}<0$. His profit is therefore $\pi_{t+1}=$ $n_{t+1}^{\alpha} k_{t+1}^{1-\alpha} K_{t+1}^{\alpha}-w_{t+1} n_{t+1}-i_{t+1}\left(k_{t+1}-\kappa_{t+1}\right)$ which, for given values of $w_{t+1}$, $i_{t+1}, K_{t+1}$ and $\kappa_{t+1}$, is maximised by choosing $n_{t+1}$ and $k_{t+1}$ so as to satisfy $\alpha n_{t+1}^{\alpha-1} k_{t+1}^{1-\alpha} K_{t+1}^{\alpha}=w_{t+1}$ and $(1-\alpha) n_{t+1}^{\alpha} k_{t+1}^{-\alpha} K_{t+1}^{\alpha}=i_{t+1}$. Since $n_{t+1}=1$ and $K_{t+1}=k_{t+1}$ in equilibrium, we may state these conditions as

$$
\begin{aligned}
w_{t+1} & =\alpha k_{t+1}, \\
i_{t+1} & =1-\alpha .
\end{aligned}
$$

In turn, entrepreneurial profits can be written as

$$
\pi_{t+1}=(1-\alpha) \kappa_{t+1} .
$$

In the first period of life an entrepreneur chooses whether or not to undertake an investment project from which capital is produced. Depending on this choice, either $\kappa_{t+1}>0$ or $\kappa_{t+1}=0$. Capital is produced using loans, $l_{t}$, acquired from young workers (i.e., workers of the same generation). The capital production technology is given by

$$
\kappa_{t+1}=A l_{t},
$$

where $(A>0) .{ }^{5}$ In addition to loans, an investment project requires a certain amount of entrepreneurial effort, $e_{t}$, which we assume to be proportional to the scale of the project, as measured by the size of loan: that is, $e_{t}=\varepsilon l_{t}(\varepsilon>0)$. Entrepreneurs are heterogeneous in terms of this effort, which is higher for some than for others. This may be thought of as reflecting idiosyncratic endowments of technical capabilities (skills, knowledge, expertise and the like) which determine entrepreneurs' efficiency in capital production. We capture this through differences in $\varepsilon$ which, for simplicity, is specified to be uniformly distributed on the unit interval with probability density function $f(\varepsilon)=1$. Accordingly, $\int_{\underline{\varepsilon}}^{\bar{\varepsilon}} f(\varepsilon) \mathrm{d} \varepsilon=\bar{\varepsilon}-\underline{\varepsilon}$ gives a measure of entrepreneurs for whom $\varepsilon \in(\underline{\varepsilon}, \bar{\varepsilon})$.

An entrepreneur's final income, $m_{t+1}$, may be deduced as follows. Recall that the interest rate on loans used for capital production is $\rho$. Accordingly, either $m_{t+1}=$ $\pi_{t+1}-(1+\rho) l_{t}$ if an entrepreneur engaged in such production $\left(\kappa_{t+1}>0\right)$, or $m_{t+1}=0$ if an entrepreneur abstained from this $\left(\kappa_{t+1}=0\right)$. Equivalently, using (4) and (5), we have

\footnotetext{
4 This aggregate externality - a common feature of endogenous growth models - allows us to work with a simple $A K$ technology, where the social returns to capital are constant. Our main results would not change were we to assume diminishing returns to capital, instead.

5 In this framework, entrepreneurs have perfect access to the loans market. For a general equilibrium model with occupational choice, heterogeneous agents, imperfect enforcement and costly intermediation, see Antunes et al. (2015).
} 


$$
m_{t+1}= \begin{cases}M l_{t} & \text { if } \kappa_{t+1}>0 \\ 0 & \text { if } \kappa_{t+1}=0\end{cases}
$$

where $M=(1-\alpha) A-(1+\rho)$.

An entrepreneur's final utility, $u_{t}$, may also be derived straightforwardly. Assuming linear disutility from effort in the production of capital, either $u_{t}=m_{t+1}-e_{t}$ or $u_{t}=0$ depending on whether or not capital production is undertaken. Given (6), and recalling that $e_{t}=\varepsilon l_{t}$, it follows that

$$
u_{t}= \begin{cases}(M-\varepsilon) l_{t} & \text { if } \kappa_{t+1}>0 \\ 0 & \text { if } \kappa_{t+1}=0\end{cases}
$$

As indicated above, the key decision for an entrepreneur is whether or not to engage in capital production when young. The condition for doing so is realised from (7) as $M-\varepsilon \geq 0$, or

$$
\varepsilon \leq M \equiv \bar{\varepsilon}
$$

This expression defines a critical level of required effort, $\bar{\varepsilon}$, such that capital production is undertaken (abstained from) by an entrepreneur for whom $\varepsilon \leq \bar{\varepsilon}(\varepsilon>\bar{\varepsilon})$.

\subsection{Growth}

The dynamic general equilibrium of the economy is summarized by a capital accumulation path which describes a process of long-run, endogenous growth. This path is determined as follows.

The quantity $\bar{\varepsilon}$ in (8) gives the fraction of young entrepreneurs who engage in capital production, the total amount of which is therefore $\bar{\varepsilon} \kappa_{t+1}$. This must be equal to $k_{t+1}$, the total amount of capital that is used by all old entrepreneurs in the production of output. Thus, from (5), $k_{t+1}=\bar{\varepsilon} A l_{t}$. Since the total amount of loans, $l_{t}$, is equal to the total wage incomes of workers, $w_{t}$, it follows from (2) that $l_{t}=\alpha k_{t}$. Combining these observations, we derive the equilibrium growth rate of the economy as

$$
\frac{k_{t+1}}{k_{t}}=\bar{\varepsilon} A \alpha \equiv g .
$$

The key factor in determining growth is the population of capital producers. Any aspect of the environment that influences $\bar{\varepsilon}$ will also influence $g$. In the present circumstances of perfect markets and perfect governance, it is simply the fundamentals of technology that matter. As shown in (8), $\bar{\varepsilon}$ is determined by $M$ which depends only on the return from, and cost of, undertaking capital production. The higher is $A$ or the lower is $\rho$ the higher is both $\bar{\varepsilon}$ and $g$ as the greater is the number of entrepreneurs who choose to be producers of capital. 


\section{An economy with organized crime}

We introduce crime into the model by considering the case in which entrepreneurs are exposed to extortion by an illicit organization — a crime syndicate or cartel—which we refer to as the mafia for shorthand. ${ }^{6}$ Like all other agents, the mafia behaves optimally by choosing its racketeering activities so as to maximise its (expected) payoff. Since workers are unaffected by such activities, their behavior remains the same as before and we do not repeat our description of this. ${ }^{7}$

\subsection{Law enforcers}

Implicit in the model is a system of law enforcement designed to obstruct and prevent, detect and prosecute, criminal behavior. For convenience, we refer to enforcers of the law as those immediately responsible for crime prevention - that is, the police, which has a measure of unit mass. ${ }^{8}$ In the context of the present environment, it is assumed that the police executes its duties in full accordance with the above objectives for mitigating crime. In return for this, each police official is paid a salary of $s_{t}$, which is financed by lump-sum taxes on workers and which is saved in the same manner as workers.

\subsection{Entrepreneurs}

Only those entrepreneurs who choose to produce capital are subject to extortion, since only these agents earn a positive income in accordance with (6). We assume that each of them faces a probability, $p \in(0,1)$, of being preyed upon $(1-p$ being the probability of avoiding this). One may think of this probability as reflecting the coverage and quality of policing when law-enforcement is functioning at its most effective level (i.e., when there is no failure in governance, other than the practical and technical difficulties in detecting and prosecuting offenders). The more effective is law-enforcement, the lower is $p$ and the greater is an entrepreneur's protection against predation.

From each capital producer, the mafia extorts a payment of $x_{t+1}^{c}$, which we assume to be a fraction of a capital producer's income, $x_{t+1}^{c}=\chi^{c} m_{t+1}\left(\chi^{c} \in(0,1)\right)$. Any entrepreneur who refuses to concede this payment is threatened with some personal damage, $d_{t+1}^{c}$, which we also assume to be proportional to entrepreneurial income, $d_{t+1}^{c}=\delta^{c} m_{t+1}\left(\delta^{c}>0\right)$. This punishment may vary in severity. What matters is the

\footnotetext{
${ }^{6}$ For the purposes of our analysis, we treat the existence of criminal activity as given. The incentives for individuals to engage in such activity is elucidated in the pioneering work of Becker (1968). Our focus is different, being centered on the effects (rather than causes) of crime when this is perpetrated by a wellestablished, organized criminal network.

7 The only change to the circumstances of workers is a lump-sum tax, which is used to pay the salary of law enforcement officials. This is only relevant to computing the dynamic general equilibrium, as we elucidate at the appropriate time.

8 This is largely for expositional purposes. Our analysis may be extended, or interpreted more broadly, to cover the functioning of higher levels of law enforcement (i.e., the judiciary).
} 
threat that it exists, which is the means by which the mafia seeks to enforce its illicit profiteering.

Given the above, we may deduce the expected utility of an entrepreneur, $E\left(u_{t}\right)$, in the presence of organized crime. The entrepreneur earns an income of $m_{t+1}$, as given in (6). For a non-producer of capital $\left(\kappa_{t+1}=0\right)$, this is also his final expected utility: that is, $E\left(u_{t}\right)=0$. For a producer of capital $\left(\kappa_{t+1}>0\right)$, utility is determined as follows. With probability $p$, the entrepreneur is confronted by the mafia, in which case he forfeits $x_{t+1}^{c}$ amount of income if he succumbs to extortion, or incurs a disutility of $d_{t+1}^{c}$ if he resists being extorted. With probability $1-p$, the entrepreneur avoids the mafia, in which case he suffers neither of these losses. Accordingly, either $E\left(u_{t}\right)=$ $p\left(m_{t+1}-x_{t+1}^{c}-e_{t}\right)+(1-p)\left(m_{t+1}-e_{t}\right)=m_{t+1}-p x_{t+1}^{c}-e_{t}$ or $E\left(u_{t}\right)=$ $p\left(m_{t+1}-d_{t+1}^{c}-e_{t}\right)+(1-p)\left(m_{t+1}-e_{t}\right)=m_{t+1}-p d_{t+1}^{c}-e_{t}$, where $e_{t}$ is recalled to be the amount of required effort to engage in capital production. Naturally, an entrepreneur is willing to comply with the mafia's demands if $x_{t+1}^{c} \leq d_{t+1}^{c}$ - that is, if the cost of paying the mafia is no greater than the cost of not doing so. From above, we may write this condition as $\chi^{c} \leq \delta^{c}$. Assuming that this is satisfied (which we verify subsequently), the expected utility of an entrepreneur may be computed as

$$
E\left(u_{t}\right)= \begin{cases}{\left[\left(1-p \chi^{c}\right) M-\varepsilon\right] l_{t}} & \text { if } \kappa_{t+1}>0 \\ 0 & \text { if } \kappa_{t+1}=0\end{cases}
$$

Like before, an entrepreneur will choose to engage in capital production if his expected utility from doing so is no less than his expected utility from not doing so. From (10), this condition is given formally as $\left(1-p \chi^{c}\right) M-\varepsilon \geq 0$, or

$$
\varepsilon \leq\left(1-p \chi^{c}\right) M \equiv \bar{\varepsilon}^{c}
$$

As in (8), this expression defines a critical level of required effort, $\bar{\varepsilon}^{c}$, below (above) which an entrepreneur will choose to engage in (abstain from) capital production. Evidently, $\bar{\varepsilon}^{c}<\bar{\varepsilon}$ for any $p, \chi^{c} \in(0,1)$, which shows that crime has the effect of deterring capital production by some entrepreneurs who would have otherwise engaged in this venture. This follows from the fact that the expected payoff from such a venture is reduced when crime exists due to the potential extra cost associated with extortion. $^{9}$

\subsection{Organized criminals}

The mafia seeks to extort money from capital producers by intimidating them with the threat of violence should they refuse to comply. This way of modelling organized crime is common in the academic literature (e.g., Alexeev et al. 2004; Kugler et al. 2003; Shelling 1984), and accords closely with the generally accepted definition of such

\footnotetext{
9 This is consistent with the empirical observation that entrepreneurs perceive racketeering as an extra risky expense in doing business (e.g., Daniele and Marani 2010; Kroska and Robeck 2006; Peri 2004).
} 
activitity amongst criminologists. ${ }^{10}$ As indicated earlier, we treat the crime syndicate as a rational decision maker whose objective is to maximise its expected payoff from extortion.

We assume that the mafia faces a probability, $q \in(0,1)$, of succeeding in its racketeering by evading arrest and prosecution $(1-q$ being the probability of failing in this). Again, one may think of this probability as depending on the quality and effectiveness of the legal system: the better functioning is this system, the lower is $q$ and the lower is the mafia's prospect of escaping the clutches of the law. We suppose that, in the event of being caught, the mafia incurs a punishment, which includes the seizure of at least some of its illicit earnings. In accordance with other analyses (as well as observed practice), we consider the severity of the punishment as being commensurate with the gravity of the offence (the level of extortion in our case). We capture this by specifying $\gamma x_{t+1}^{c}(\gamma \in(0,1))$ as the amount of extortion payment that the mafia stands to lose should it suffer legal retribution. ${ }^{11}$

Another cost to the mafia relates to the means by which it seeks to enforce its illicit profiteering. As alluded to already, this involves the use of threats of violence against non-compliant individuals who face a penalty of $d_{t+1}^{c}$ if they do not succumb to the mafia's demands. Such threats must be credible, and we assume that it is costly for the mafia to ensure this. Specifically, we suppose that the cost of threats is given by $\Delta d_{t+1}^{c}$ $(\Delta>0)$, being proportional to the amount of damage inflicted on victims. This cost is incurred ex ante and is independent of the number of potential victims: the mafia must arm itself before knowing which individuals are susceptible to extortion, after which the same threat can be applied to all individuals. ${ }^{12}$

With the foregoing in mind, we may compute the mafia's expected payoff, $E\left(v_{t}\right)$, as follows. Its illegal income from each of its prey is $x_{t+1}^{c}$. With probability $q$, all of this income is retained. With probability $1-q$, only $(1-\gamma) x_{t+1}^{c}$ of this income is retained. The mafia's expected earnings from each of its victims is therefore $q x_{t+1}^{c}+(1-q)(1-$ $\gamma) x_{t+1}^{c}=[1-\gamma(1-q)] x_{t+1}^{c}$. The number of potential victims is given by $\bar{\varepsilon}^{c}$ in (11), and the probability that any one of them is susceptible to extortion is given by $p$. The product of these terms represents the mafia's extortion base. Accordingly, the mafia's total expected earnings from racketeering is deduced to be $[1-\gamma(1-q)] x_{t+1}^{c} p \bar{\varepsilon}^{c}$. Deducted from this is the cost of enforcing extortion, $\Delta d_{t+1}^{c}$. Recalling that $x_{t+1}^{c}=$ $\chi^{c} m_{t+1}$ and $d_{t+1}^{c}=\delta^{c} m_{t+1}$, where $m_{t+1}$ is given in (6), we arrive at the following final expression for the mafia's expected payoff:

$$
E\left(v_{t}\right)=\left\{[1-\gamma(1-q)] \chi^{c} p \bar{\varepsilon}^{c}-\Delta \delta^{c}\right\} M l_{t} .
$$

\footnotetext{
10 That is, organized crime is the perpetration of illegal activities for material benefit by coordinated groups of individuals who ply their trade through extortion, corruption and subversion using extreme violence (e.g., Kenney and Finckenauer 1995; Levi 2002).

11 This is a pecuniary punishment, but there are obviously non-pecuniary punishments as well (e.g., imprisonment). The former may be considered as encompassing the latter in the sense that it represents the illegal income that could have been earned if a criminal was not incarcerated. In any case, the separate inclusion of a non-pecuniary punishment is a trivial extension to the model that would not alter the main results.

12 The mafia needs only to demonstrate that it has the capabilities of inflicting harm. At the extreme, its possession of just one explosive device, one firearm or one ruthless thug poses the same threat to all potential victims.
} 
In choosing its optimal behavior, the mafia takes into account the influence of its actions on the optimal behavior of its prey. Specifically, the mafia realises that a greater level of extortion, $\chi^{c}$, has two effects: the first is to reduce the number of potential victims, $\bar{\varepsilon}^{c}$ in (11), by inducing more entrepreneurs to abstain from capital production; the second is to undermine the condition for capital producers' compliance in extortion, $\chi^{c} \leq \delta^{c}$, which may necessitate the use of more severe and more costly means of enforcing compliance. With these considerations in mind, the mafia chooses its level of extortion and scale of retribution so as to maximise its expected utility. Formally, its problem is given as

$$
\begin{aligned}
\max _{\chi^{c}, \delta^{c}} E\left(v_{t}\right) & =\left\{[1-\gamma(1-q)] \chi^{c} p \bar{\varepsilon}^{c}-\Delta \delta^{c}\right\} M l_{t}, \\
\text { s.t. } \bar{\varepsilon}^{c} & =\left(1-p \chi^{c}\right) M, \\
\chi^{c} & \leq \delta^{c} .
\end{aligned}
$$

The solution to this problem is derived in the Appendix as

$$
\begin{aligned}
& \chi^{c}=\delta^{c}=\frac{1}{2 p}\left\{1-\frac{\Delta}{p[1-\gamma(1-q)] M}\right\}, \\
& \bar{\varepsilon}^{c}=\frac{1}{2}\left\{M+\frac{\Delta}{p[1-\gamma(1-q)]}\right\} .
\end{aligned}
$$

These expressions have the following intuitive properties.

The fact that $\chi^{c}=\delta^{c}$ in (13) reflects the mafia's minimisation of costs in implementing its racketeering: the least costly way of exacting illicit payments from capital producers is to threaten them with an equivalent (no greater) punishment should they refuse to comply. The optimal amount of extortion, itself, is observed to be decreasing in $\Delta$, decreasing in $\gamma(1-q)$ and either decreasing or increasing in $p$. The first property shows that the level of extortion is higher, the lower is the exogenous cost to the mafia of enforcing it. The second property similarly reveals that the amount of extortion is increased when the mafia faces a lower expected punishment for its offence. ${ }^{13}$ The third property is a little more subtle, demonstrating that greater racketeering opportunities for the mafia may lead to either higher or lower levels of extortion. This follows from the fact that the extortion base, $p \bar{\varepsilon}^{c}$, may move either way as the scope for predation increases: on the one hand, a higher fraction of capital producers are able to be exploited, which tends to raise the extortion base and to exacerbate the mafia's demands; on the other hand, fewer entrepreneurs are inclined to undertake capital production, which tends to lower the extortion base and to moderate the mafia's demands.

The above results are reflected in capital production activity, as given in (14). The number of capital producers, $\bar{\varepsilon}^{c}$, is seen to be increasing in $\Delta$, increasing in $\gamma(1-q)$ and decreasing in $p$. The first and second of these properties are allied directly to the higher levels of extortion that the mafia chooses when faced with lower costs of

\footnotetext{
13 Put the other way, criminal activity is lower when the expected penalty for this activity is higher-an implication that accords with the spirit of Becker (1968).
} 
pursuing such activity (i.e., lower costs of enforcement and/or lower expected costs of prosecution). Under such circumstances, capital production is less profitable and therefore less attractive to a greater number of entrepreneurs. The third property reveals that an increase in exposure to mafia predation, whilst having an ambiguous effect on the amount of extortion, causes a net decrease in the population of capital producers: even if the mafia extorts less, fewer entrepreneurs choose to participate in capital production because of their greater prospect of being preyed upon and their greater expected loss of income, $p \chi^{c}$.

\subsection{Growth}

The equilibrium growth rate of the economy is derived as before by combining the capital market clearing condition, $k_{t+1}=\bar{\varepsilon}^{c} A l_{t}$, with the loan market clearing condition, $l_{t}=w_{t}$, and recalling the expression for $w_{t}$ in (2). ${ }^{14}$ Doing this gives

$$
\frac{k_{t+1}}{k_{t}}=\bar{\varepsilon}^{c} A \alpha \equiv g^{c}
$$

Evidently, growth is now influenced by factors other than technology since the number of capital producers is influenced likewise. In particular, $g^{c}$ is reduced by any reduction in $\bar{\varepsilon}^{c}$ caused by an increase in the extent of criminal activity, as alluded to above. Comparing (15) with (9), making use of our earlier observation that $\bar{\varepsilon}^{c}<\bar{\varepsilon}$, we arrive at the conclusion that $g^{c}<g$ : growth in a crime-ridden economy is lower than growth in a crime-free economy. ${ }^{15}$

\section{An economy with organized crime and corruption}

Our modelling of corruption centers on the behavior of law enforcers and their relationship with the crime cartel. In our previous analysis we assumed that the police acted with full integrity in executing its crime prevention duties. This meant that capital producers had at least some chance of being protected against mafia predation. We now consider the case in which police officers are corruptible in the sense of being potentially willing to accept bribes from the mafia in return for turning a blind eye to the mafia's activities. ${ }^{16}$ Like before, the behavior of workers is unaffected, and we focus only on the new dimensions of the model.

\footnotetext{
14 Note that neither the mafia's illegal income, nor law enforcers' legal income, contribute to the amount of loanable funds. The reason for the former is that each generation of mafiosi extracts its income in the second period of life. The reason for the latter is that law enforcers' salaries are merely lump-sum tax transfers from workers, which net out of aggregate savings.

15 As indicated previously, (8) and (11) imply that $\bar{\varepsilon}^{c}<\bar{\varepsilon}$ must be true, given that both $p \in(0,1)$ (which we obviously assume) and $\chi^{c} \in(0,1)$ (which we need to ensure). From (12), the parameter restriction needed for the latter is $[1-\gamma(1-q)] M p>\Delta>[1-\gamma(1-q)] M p(1-2 p)$. The first inequality $\left(\chi^{c}>0\right)$ is sufficient for delivering $\bar{\varepsilon}^{c}<\bar{\varepsilon}$.

16 For simplicity, we shall assume that all police officers are susceptible to bribery. Our main results would not change were we to consider some fraction of them as being non-corruptible.
} 


\subsection{Law enforcers}

As mentioned previously, police officers earn a salary of $s_{t}$ when young, which is saved at the rate of interest $\rho$ to finance their consumption when old. A police officer who is corrupt seeks to supplement his old-age consumption by accepting bribe payments from the mafia, which is then free to commit its offences. We assume that the amount of bribe demanded for each offence, $b_{t+1}$, is proportional to the mafia's income from that offence: that is, $b_{t+1}=(1-\beta) x_{t+1}^{c c}(\beta \in(0,1)) .{ }^{17}$ Using higher case notation to denote aggregate variables, the total bribe income of each corrupt law enforcer is then given by $B_{t+1}=(1-\beta) X_{t+1}^{c c} \cdot{ }^{18}$

Bribe-taking is risky because of the possibility of being caught and prosecuted. We assume that this event is avoided with probability $r \in(0,1)$. Otherwise (with probability $1-r$ ), corruption is exposed and each perpetrator of it is subject to a punishment of $f_{t+1}$ which may be pecuniary (e.g., a fine) and/or non-pecuniary (e.g., imprisonment). We suppose that this punishment is set by the judiciary in a way that is commensurate with the scale of the mafia's racketeering: specifically, we set $f_{t+1}=\phi X_{t+1}^{c c}(\phi>0) .{ }^{19}$ The probability that corruption goes undetected reflects the government's imperfect monitoring of such activity and may be regarded as another measure of the quality of governance in model: the better is this quality, the lower is $r$ and the greater is the likelihood that corrupt behavior is detected.

Depending on whether bribes are refused or accepted, a law-enforcer expects a payoff of either $(1+\rho) s_{t}$, or $r\left[(1+\rho) s_{t}+B_{t+1}\right]+(1-r)\left[(1+\rho) s_{t}+B_{t+1}-\right.$ $\left.f_{t+1}\right]=(1+\rho) s_{t}+B_{t+1}-(1-r) f_{t+1}$. It follows that bribes will be accepted if $(1+\rho) s_{t}+B_{t+1}-(1-r) f_{t+1} \geq(1+\rho) s_{t}$, or $B_{t+1} \geq(1-r) f_{t+1}$. Under our previous assumptions, this condition may be re-stated as $1-\beta \geq(1-r) \phi$. Intuitively, a police officer is willing to accept a bribe payment that is at least equal to the expected punishment for his crime.

\subsection{Entrepreneurs}

The existence of corruption affects entrepreneurs both directly and indirectly. The direct effect is a loss of protection against mafia predation due to the police's complicity in this activity. This is captured by setting $p=1$. The indirect effect is a change in the level of extortion due to the mafia's need to pay bribes for this complicity. This is reflected in the optimal choice of $x_{t+1}^{c c}=\chi^{c c} m_{t+1}$, to which we attend later.

\footnotetext{
17 We distinguish $x_{t+1}^{c c}$ from $x_{t+1}^{c}$ since, as we shall see, the level of extortion when corruption exists is different from the level of extortion when corruption is absent.

18 We do not differentiate between law enforcers. Each one of them earns the same bribe income, whether due to the same number of capital producers under each one's protection, or the sharing of illicit earnings amongst all of them.

19 This assumption reflects the idea that the judiciary may be able to observe the amount of extortion, but not the amount of bribe payments. For example, whilst capital producers may be quite willing to report how much the mafia has extorted from them, corrupt law enforcers would want to conceal their bribe income. The most that the judiciary knows is that bribes are proportional to the amount of extortion, and therefore sets its punishment in the same way.
} 
Like before, an entrepreneur who abstains from capital production earns a utility of $u_{t}=0$. Unlike before, an entrepreneur who engages in capital production earns a utility of either $u_{t}=m_{t+1}-x_{t+1}^{c c}-e_{t}$ or $u_{t}=m_{t+1}-d_{t+1}^{c c}-e_{t}$, depending on whether or not he surrenders to extortion, where $d_{t+1}^{c c}=\delta^{c c} m_{t+1} \cdot{ }^{20}$ The condition for surrendering is unchanged-that is, $x_{t+1}^{c c} \leq d_{t+1}^{c c}$, or $\chi^{c c} \leq \delta^{c c}$. Assuming that this is satisfied, an entrepreneur's payoff under alternative choices is

$$
u_{t}= \begin{cases}{\left[\left(1-\chi^{c c}\right) M-\varepsilon\right] l_{t}} & \text { if } \kappa_{t+1}>0 \\ 0 & \text { if } \kappa_{t+1}=0\end{cases}
$$

Following our previous analysis, we may deduce from (16) that $\left(1-\chi^{c c}\right) M-\varepsilon \geq 0$ is the condition for an entrepreneur to undertake capital production, which we may write as

$$
\varepsilon \leq\left(1-\chi^{c c}\right) M \equiv \bar{\varepsilon}^{c c}
$$

As before, this expression defines a critical level of required effort, $\bar{\varepsilon}^{c c}$, below (above) which an entrepreneur will choose to undertake (forego) capital production. Also like before, a comparison with (8) reveals that $\bar{\varepsilon}^{c c}<\bar{\varepsilon}$ for any $\chi^{c c} \in(0,1)$, which reestablishes the negative effect of extortion on the population of capital producers. Of more interest to us is a comparison with (11), from which we observe that $\bar{\varepsilon}^{c c} \lessgtr \bar{\varepsilon}^{c}$ according to $\chi^{c c} \gtrless p \chi^{c}$. This suggests the possibility that capital production may be deterred by either more or less when corruption is present than when it is absent. A sufficient condition for the former outcome is that the level of extortion is the same in the two environments. As we shall see, however, this is not generally true and the outcome is more ambiguous.

\subsection{Organized criminals}

In the presence of a corruptible police force, the mafia has the opportunity to pursue its racketeering activities with the compliance of law enforcers. It does so by extorting payments from capital producers using the threat of violence as a means of enforcement, and by offering bribes to police officers in return for their agreement to overlook such behavior. For each offence committed, the mafia's income is $x_{t+1}^{c c}-b_{t+1}$. As previously, the mafia makes its decisions optimally in a way that maximises its expected payoff.

It is plausible (though not necessary) to imagine that the mafia's prospects for evading arrest and prosecution are better (or at least no worse) when corruption exists than when it is absent. Accordingly, we now define $q^{\prime} \geq q$ as the probability that the mafia escapes with its ill-gotten gains. ${ }^{21}$ We continue to assume that, in the alternative

\footnotetext{
20 We distinguish $d_{t+1}^{c c}$ from $d_{t+1}^{c}$ for the same reason that we distinguish $x_{t+1}^{c c}$ from $x_{t+1}^{c}$.

21 One may conceive of this probability as depending on $r$, the probability that corrupt law enforcers also evade prosecution. For example, the mafia may face the possibility of apprehension only if its conspirators are apprehended, in which case the mafia's probability of evading arrest might be $q^{\prime}=r+(1-r) q>q$, where $q$ may represent the probability that law enforcers do not squeal (maintain a conspiracy of silence).
} 
event of being apprehended, the mafia loses a fraction of its final income, which is the income left over after paying bribes. This potential cost to the mafia is given by $\gamma\left(x_{t+1}^{c c}-b_{t+1}\right)$. The other cost to the mafia is its outlay on enforcing extortion, which is given similarly to before as $\Delta d_{t+1}^{c c}$.

Given the above, we may deduce the mafia's expected payoff, $E\left(v_{t}\right)$, as follows. Its net income from each capital producer is $x_{t+1}^{c c}-b_{t+1}$. All of this income is pocketed with probability $q^{\prime}$, whilst only $(1-\gamma)\left(x_{t+1}^{c}-b_{t+1}\right)$ of it is kept with probability $1-q^{\prime}$. The mafia's expected income per victim is therefore given by $q^{\prime}\left(x_{t+1}^{c c}-b_{t+1}\right)+\left(1-q^{\prime}\right)(1-\gamma)\left(x_{t+1}^{c c}-b_{t+1}\right)=\left[1-\gamma\left(1-q^{\prime}\right)\right]\left(x_{t+1}^{c c}-b_{t+1}\right)$. The number of potential victims is given by $\bar{\varepsilon}^{c c}$ in (17), all of whom can be preyed upon with certainty at a cost of $\Delta d_{t+1}^{c c}$. Collecting these observations together, we arrive at the following expression for the mafia's expected payoff:

$$
E\left(v_{t}\right)=\left\{\left[1-\gamma\left(1-q^{\prime}\right)\right] \chi^{c c} \beta \bar{\varepsilon}^{c c}-\Delta \delta^{c c}\right\} M l_{t} .
$$

As before, the mafia chooses its optimal behavior in acknowledgement of the behavior of others. In addition to entrepreneurs' decisions as to whether or not to undertake capital production and whether or not to surrender to extortion, there is the consideration of luring police officers into corruption. Consequently, the mafia takes into account (17) (the engagement of entrepreneurs in capital production), $\chi^{c c} \leq \delta^{c c}$ (the compliance of capital producers in extortion) and $1-\beta \geq(1-r) \phi$ (the participation of law enforcers in bribe-taking). The mafia's decision problem is, therefore, given as

$$
\begin{gathered}
\max _{\chi^{c c}, \delta^{c c}, \beta} E\left(v_{t}\right)=\left\{\left[1-\gamma\left(1-q^{\prime}\right)\right] \chi^{c c} \beta \bar{\varepsilon}^{c c}-\Delta \delta^{c c}\right\} M l_{t}, \\
\text { s.t. } \quad \bar{\varepsilon}^{c c}=\left(1-\chi^{c c}\right) M, \\
\chi^{c c} \leq \delta^{c c}, \\
(1-r) \phi \leq 1-\beta .
\end{gathered}
$$

Solving this problem, as outlined in the Appendix, yields

$$
\begin{gathered}
\chi^{c c}=\delta^{c c}=\frac{1}{2}\left\{1-\frac{\Delta}{\beta\left[1-\gamma\left(1-q^{\prime}\right)\right] M}\right\}, \\
1-\beta=(1-r) \phi, \\
\bar{\varepsilon}^{c c}=\frac{1}{2}\left\{M+\frac{\Delta}{\beta\left[1-\gamma\left(1-q^{\prime}\right)\right]}\right\} .
\end{gathered}
$$

These results can be interpreted similarly to those established earlier.

The result in (19) re-establishes that $\chi^{c c}=\delta^{c c}$, meaning that the mafia exacts extortion payments from capital producers by threatening them with the minimum damage needed for this. Similarly, the level of extortion is observed to be decreasing in $\Delta$ (the mafia's resource cost in demonstrating its threats) and decreasing in $\gamma\left(1-q^{\prime}\right)$ (the mafia's expected punishment for its crimes). Additionally, we find that the amount of extortion is increasing in $\beta$ (the fraction of mafia income left over after paying bribes). Accordingly, lower bribe payments provokes the mafia to extort more, the 
reason being simply that the mafia keeps more of its illegal income. ${ }^{22}$ The result in (20) gives the optimal bribe payment, $1-\beta$, which the mafia sets at the lowest possible level that encourages law enforcers to be corrupt (i.e., the level at which law enforcers' corruption participation constraint binds). An implication of this is that a stronger deterrent to corruption (as measured by $(1-r) \phi$ ) forces the mafia to make higher bribe payments which, in turn, induces a lower rate of extortion. ${ }^{23}$

The result in (21) demonstrates, as before, that the number of capital producers, $\bar{\varepsilon}^{c c}$, is increasing in both $\Delta$ and $\gamma\left(1-q^{\prime}\right)$ because of the effects of these cost terms on the level of extortion. Additionally, we observe that the number of capital producers is decreasing in $\beta$, which is similarly explained by the impact of this bribe factor on the level of extortion.

\subsection{Growth}

The growth rate of the economy is derived in the usual way. Equilibrium in the capital market requires $k_{t+1}=\bar{\varepsilon}^{c c} A l_{t}$, whilst equilibrium in the loan market implies $l_{t}=w_{t}$, where $w_{t}$ is given in (2). ${ }^{24}$ Consequently, we have

$$
\frac{k_{t+1}}{k_{t}}=\bar{\varepsilon}^{c c} A \alpha \equiv g^{c c} \text {. }
$$

As before, the key determinant of growth is the number of capital-producing entrepreneurs, which now depends on factors related to both crime and corruption. In particular, $g^{c c}$ is reduced by any reduction in $\bar{\varepsilon}^{c c}$ caused by an increase in extortion and bribe-taking, as indicated above. Given our earlier observation that $\bar{\varepsilon}^{c c}<\bar{\varepsilon}$, a comparison of (22) and (9) re-asserts that $g^{c c}<g$ : growth in a badly governed economy is lower than growth in a well-governed economy. ${ }^{25}$

\section{A comparison of environments}

The basic message of our analysis so far is uncontroversial and confirms what one generally presumes-namely, that an economy performs better when it is free from all crime and corruption than when it is saddled with either or both these. Our primary

\footnotetext{
22 Essentially, bribe payments act as a proportional tax on the mafia's illicit activities. A reduction in this tax encourages the mafia to engage more in these activities.

23 The effect of anti-corruption strategies (or lack of) on criminal activity is an important issue, though it is not one that we pursue in this paper. There are several analyses that do so, indicating the many nuances and complexities of the issue (e.g., Bowles and Garoupa 1997; Chang et al. 2000; Jellal and Garpoupa 2007; Polinsky and Shavell 2001).

${ }^{24}$ As explained earlier, neither the mafia's illegal income nor the salaries of law enforcers contribute to the amount of loanable funds. The same is true of law enforcers' bribe income, which is received in the second period of life.

${ }^{25}$ Like before, our earlier assertion, based on (8) and (17), that $\bar{\varepsilon}^{c c}<\bar{\varepsilon}$ for any $\chi^{c c} \in(0,1)$ requires us to ensure that the latter is true. From (19), the parameter restriction needed for this is $\left[1-\gamma\left(1-q^{\prime}\right)\right] M \beta>\Delta>$ $-\left[1-\gamma\left(1-q^{\prime}\right)\right] M \beta$. Obviously, the second inequality $\left(\chi^{c c}<1\right)$ is automatically satisfied. The first inequality $\left(\chi^{c c}>0\right)$ delivers $\bar{\varepsilon}^{c c}<\bar{\varepsilon}$.
} 
interest is the question of whether an economy is damaged by more or less if crime occurs alone than if crime co-exists with corruption. We study this as follows.

Whichever type of environment one considers, the ultimate factor in impeding growth is the mafia's extortion of capital producers. It is this which deters capital production by increasing the costs to entrepreneurs of undertaking such activity. The question of which type of environment suffers the most damage is therefore a question of which type of environment suffers the most racketeering. To be sure, a comparison of (15) and (22), together with (11) and (17), shows that whether $g^{c} \gtrless g^{c c}$ depends solely on whether $\varepsilon^{c} \gtrless \varepsilon^{c c}$ which, in turn, depends solely on whether $p \chi^{c} \lessgtr \chi^{c c}$. The last of these inequalities compares the expected extortion payment in the presence of crime alone with the extortion payment in the presence of both crime and corruption. By resolving this inequality, we resolve the other two.

From (13) and (19), we find that $p \chi^{c} \lessgtr \chi^{c c}$ according to $p[1-\gamma(1-q)] \gtrless \beta[1-$ $\left.\gamma\left(1-q^{\prime}\right)\right]$. The key parameters in this condition are $p$ (the fraction of potential victims exposed to the mafia in a crime-only environment) and $\beta$ (the fraction of post-bribe income available to the mafia in a crime-plus-corruption environment). Essentially, these parameters substitute for each other in determining the mafia's potential returns from extortion. As we have seen, a higher value of $p$ implies a higher value of $p \chi^{c}$ (even if $\chi^{c}$ falls), and a higher value of $\beta$ implies a higher value of $\chi^{c c}$. It follows that $p \chi^{c}>\chi^{c c}$ is more (less) likely the greater (lower) is $p$ relative to $\beta$. From above, this translates into a greater (lower) likelihood that $\varepsilon^{c}<\varepsilon^{c c}$ and $g^{c}<g^{c c}$. ${ }^{26}$

The above analysis demonstrates how the effects of organized crime on economic activity may depend on the participation in corruption by those responsible for preventing such crime. A priori, this dependence is ambiguous in the sense that the damage inflicted by organized crime may be greater or less when corruption exists than when it is absent. This is our key result which has not, to our knowledge, been established before.

The ambiguous prediction of our analysis may appear somewhat surprising. One might typically presume that the combination of organized crime and corruption is more damaging to an economy than organized crime alone. We have articulated the reasons why this may not be the case.

\section{Conclusion}

This paper has sought to cast further light on the macroeconomic implications of organized crime and its interaction with corruption. These two phenomena are amongst the most vivid examples of poor quality governance and badly functioning institutions. Their adverse effects on growth and development are well documented, and the fight against each of them remains high on the agendas of national and international agencies. What is less well understood is the extent to which their impacts might be reinforced or subdued through linkages between them. Making in-roads to this has been our primary objective in this paper.

\footnotetext{
${ }^{26}$ Comparing the final outcomes for $\bar{\varepsilon}^{c}$ and $\bar{\varepsilon}^{c c}$ in (14) and (21), one observes that $\bar{\varepsilon}^{c} \gtrless \bar{\varepsilon}^{c c}$ according to $p[1-\gamma(1-q)] \lessgtr \beta\left[1-\gamma\left(1-q^{\prime}\right)\right]$ —xactly the reverse condition for $p \chi^{c} \gtrless \chi^{c}$, as suggested earlier.
} 
Our analysis shows how organized crime alone creates an unfavorable climate for business activity by raising the costs of this activity through extortion. The upshot is that growth is lower than would otherwise be the case. This is what one would expect, but our modelling strategy is designed to go much further in demonstrating how the impact of organized crime may be conditional on the presence of corruption. As our results indicate, this conditionality could go either way-organized crime may be more or less damaging if it co-exists with corruption. The intuition is that since corruption operates as a tax on criminality, the outcome depends on the expected payoffs of the crime syndicate when having to pay bribes to corrupt law officers. This, in turn, depends on the trade-off between a lower supply of crimes and the probability these crimes are more likely to be successful. If corruption, despite its direct cost to criminals, leads to higher (lower) expected payoff from extortion, then the growth-diminishing effect of crime is greater (smaller) in the presence of corruption. Ultimately, however, whether organized crime distorts economic growth by a different degree when acting alone compared to when co-existing with corruption, is an empirical question. This is a task undertaken in a companion paper, by Neanidis et al. (2017), with a focus on Italian regions, admittedly a geographical area historically saddled with both types of illicit activities.

Open Access This article is distributed under the terms of the Creative Commons Attribution 4.0 International License (http://creativecommons.org/licenses/by/4.0/), which permits unrestricted use, distribution, and reproduction in any medium, provided you give appropriate credit to the original author(s) and the source, provide a link to the Creative Commons license, and indicate if changes were made.

\section{Appendix A: Solution to the Mafia's problem in the absence of corruption}

The results in (13) and (14) are obtained by setting up the Lagrangian,

$$
L=\left\{[1-\gamma(1-q)] p \chi^{c}\left(1-p \chi^{c}\right) M-\Delta \delta^{c}\right\} M l_{t}+\lambda_{t}\left(\delta^{c}-\chi^{c}\right),
$$

where $\lambda_{t}$ is the Lagrange multiplier. The optimality and complementary slackness conditions are

$$
\begin{gathered}
{[1-\gamma(1-q)] p\left(1-2 p \chi^{c}\right) M^{2} l_{t}-\lambda_{t}=0,} \\
-\Delta M l_{t}+\lambda_{t}=0, \\
\lambda_{t}\left(\delta^{c}-\chi^{c}\right), \lambda_{t} \geq 0, \delta^{c} \geq \chi^{c} .
\end{gathered}
$$

From (A2), we have $\lambda_{t}=\Delta M l_{t}>0$, which implies that $\delta^{c}=\chi^{c}$ from (A3). Substitution into (A1) gives the result in (13), which may be substituted into (11) to arrive at the result in (14). 


\section{Appendix B: Solution to the Mafia's problem in the presence of corruption}

The results in (19)-(21) are obtained by setting up the Lagrangian,

$$
\begin{aligned}
L= & \left\{\left[1-\gamma\left(1-q^{\prime}\right)\right] \chi^{c c} \beta\left(1-\chi^{c c}\right) M-\Delta \delta^{c c}\right\} M l_{t} \\
& +\lambda_{1 t}\left(\delta^{c c}-\chi^{c c}\right)+\lambda_{2 t}[1-\beta-(1-r) \phi],
\end{aligned}
$$

$\lambda_{i t}(i=1,2)$ is the Lagrange multiplier. The optimality and complementary slackness conditions are

$$
\begin{gathered}
{\left[1-\gamma\left(1-q^{\prime}\right)\right] \beta\left(1-2 \chi^{c c}\right) M^{2} l_{t}-\lambda_{1 t}=0,} \\
-\Delta M l_{t}+\lambda_{1 t}=0, \\
{\left[1-\gamma\left(1-q^{\prime}\right)\right] \chi^{c c}\left(1-\chi^{c c}\right) M^{2} l_{t}-\lambda_{2 t}=0,} \\
\lambda_{1 t}\left(\delta^{c c}-\chi^{c c}\right), \lambda_{1 t} \geq 0, \delta^{c c} \geq \chi^{c c}, \\
\lambda_{2 t}[1-\beta-(1-r) \phi] \geq 0, \lambda_{2 t} \geq 0,1-\beta \geq(1-r) \phi .
\end{gathered}
$$

From (B2), we have $\lambda_{1 t}=\Delta M l_{t}>0$, which implies that $\delta^{c c}=\chi^{c c}$ from (B4). Substitution into (B1) gives the result in (19), which may be substituted into (17) to arrive at the result in (21). From (B3) we have $\lambda_{2 t}=\left[1-\gamma\left(1-q^{\prime}\right)\right] \chi^{c c}\left(1-\chi^{c c}\right) M^{2} l_{t}>$ 0 , which implies that $1-\beta=(1-r) \phi$ from (B5). This is the result in (20).

\section{References}

Alexeev, M., Janeba, E., Osborne, S.: Taxation and evasion in the presence of extortion by organized crime. J. Comp. Econ. 32, 375-387 (2004)

Antunes, A., Cavalcanti, T., Villamil, A.: The effects of credit subsidies on development. Econ. Theory 58(1), 1-30 (2015)

Becker, G.: Crime and punishment: an economic approach. J. Politi. Econ. 76, 167-217 (1968)

Becker, G., Stigler, G.: Law enforcement, malfeasance, and the compensation of enforces. J. Legal Stud. 3, 1-19 (1974)

Besley, T., MacLaren, J.: Taxes and bribery: the role of wage incentives. Econ. J. 103, 119-141 (1993)

Blackburn, K., Chivers, D.: Fearing the worst: the importance of uncertainty for inequality. Econ. Theory 60(2), 345-370 (2015)

Bowles, R., Garoupa, N.: Casual police corruption and the economics of crime. Int. Rev. Law Econ. 17, 75-87 (1997)

Buscaglia, E., Van Dijk, J.J.M.: Controlling Organized Crime and Corruption in the Public Sector. Forum on Crime and Society, vol. 3(1-2). United Nations Publications, New York (2003)

Center for the Study of Democracy: Examining the Links Between Organised Crime and Corruption. Center for the Study of Democracy, Sofia (2010)

Chang, J.J., Lai, C.C., Yang, C.C.: Casual police corruption and the economics of crime: further results. Int. Rev. Law Econ. 20, 35-51 (2000)

Daniele, V., Marani, U.: Organized crime and foreign direct investments: the Italian case. CESifo Working Paper No. 2416 (2010)

Eurobarometer: Opinions on organized, cross-border crime and corruption. Special Eurobarometer 245/Wave 64.3-TNS Opinion and Social (2006)

Garoupa, N., Klerman, D.: Corruption and the optimal use of nonmonetary sanctions. Int. Rev. Law Econ. 24, 219-225 (2004)

Jellal, M., Garpoupa, N.: Information, corruption and optimal law enforcement. Eur. J. Law Econ. 23, 59-69 (2007) 
Kenney, D.J., Finckenauer, J.O.: Organized Crime in America. Wadsworth Publishing Company, Belmont (1995)

Kroska L., Robeck, K.: The impact of crime on the enterprise sector: transition versus non-transition countries. Working Paper 97, European Bank for Reconstruction and Development (2006)

Kugler, M., Verdier, T., Zenou, Y.: Organized crime, corruption, and punishment. IUI, The Research Institute of Industrial Economics, Working Paper No. 600 (2003)

Levi, M.: The organization of serious crime. In: Maguire, M., Morgan, R., Reiner, R. (eds.) Handbook of Criminology. Oxford University Press, Oxford (2002)

Mazzitelli, A.L.: Transnational organized crime in West Africa: the additional challenge. Int. Aff. 83(6), 1071-1090 (2007)

Mookherjee, D., Png, I.: Monitoring vis-a-vis investigation in enforcement of law. Am. Econ. Rev. 82, 556-565 (1992)

Neanidis, K.C., Rana, M.P., Blackburn, K.: An Empirical Analysis of Organized Crime, Corruption and Economic Growth. University of Manchester, Manchester (2017)

Peri, G.: Socio-cultural variables and economic success: evidence from Italian provinces 1951-1991. Berkeley Electron. J. Top. Macroecon. 4(1), 12 (2004)

Polinsky, M., Shavell, S.: Corruption and optimal law enforcement. J. Public Econ. 81, 1-24 (2001)

Sergi, B.S., Qerimi, Q.: Fighting corruption and organized crime as a means of socio-economic development in South-East Europe. South-East Eur. Rev. 2, 81-94 (2007)

Shelling, T.: Economics and criminal enterprise. In: Shelling, T. (ed.) Choice and Consequences, pp. 158178. Harvard University Press, Cambridge (1984) 